\title{
Fundamentos do 'Paradigma Metodológico Causal' nas Ciências Sociais
}

\section{Resumo}

O presente ensaio trata da lógica subjacente dos chamados 'métodos quantitativos' nas ciências sociais. A especificação desta lógica subjacente se enquadra na tentativa de estabelecer a existência de uma lógica unitária abrangente para as duas abordagens mais gerais da metodologia nas ciências sociais, a saber, a qualitativa e a quantitativa. Esta lógica unitária é procurada a partir da noção de 'paradigmas científicos' de T. Kuhn (1975), sendo que as questões metodológicas representam, por 'hipótese de trabalho', um caso especial de paradigma científico, diferenciando-se dos outros paradigmas na ausência de generalizações simbólicas, anomalias, e 'revoluções', e pelo papel substantivo dos modelos procedimentais, principalmente de fornecimento de evidências. Com este objetivo, o trabalho realiza uma revisão esquemática dos paradigmas Kuhnianos, e depois analisa a tradição metodológica chamada quantitativa nas ciências sociais - especialmente na sociologia - , à luz de tais paradigmas, cunhando a expressão 'paradigma metodológico causal' (PMC). Através, pois, do enquadramento paradigmático das duas abordagens (sendo que a dos métodos qualitativos ainda é deixada para o futuro desta linha de pesquisa), será possível verificar se a interface entre as duas abordagens responde a uma lógica 'metodológica' unitária subjacente; em caso afirmativo se reduziriam - ou até se eliminariam - as respostas conflitantes sobre questões de escolha e combinações entre os dois tipos de práticas, subsidiando a formalização de estratégias do tipo 'quali-quanti'. Note-se, finalmente, que a lógica subjacente ao PMC envolve a combinação da noção de causa, lato sensu, com

\footnotetext{
* Doutor em Sociologia. Professor de Sociologia do Programa de Pós Graduação em Sociologia da Universidade Federal do Rio Grande do Sul (Brasil). E-mail: jm.fandino.marino@gmail.com
} 
o modelo experimental e seus desdobramentos, sem que isto pressuponha que o papel instrumental dos métodos qualitativos no próprio PMC passe pela noção de causa, ou pela experimentação, ou por comparações do tipo que for.

Palavras-chave: Métodos quantitativos em ciências sociais. Paradigma metodológico causal. Métodos quali-quanti.

\section{Foundations of the "Causal Methodological Paradigm" in social sciences}

\section{Abstract}

The present paper reflects on the underlying logic of the so-called 'quantitative methods' applied to social sciences. The account of such underlying logic is framed within the efforts towards establishing the existence of a single comprehensive logic for both the most typical approaches to social sciences methodology, namely the qualitative and the quantitative. This single logic is pursued by means of Kuhn's concept of "scientific paradigm" (1975), where methodological issues represent, while 'work assumption', a particular instance of scientific paradigm, distinguished from other paradigms by the absence of symbolic generalizations, anomalies and 'revolutions', and by the substantive role of procedural models, primarily regarding evidence provision. For this purpose, the paper presents a concise review of Kuhninan paradigms and, then, analyzes the so called quantitative methodological tradition in social sciences - particularly in sociology - in the light of such paradigms, and coining the term 'causal methodological paradigm' (CMP). Therefore, by means of the paradigmatic framing of these two approaches (though that of qualitative method is postponed to a future step in this research line), it will be possible to establish whether the interface between the two approaches meet the assumption of an underlying methodological common logic. In the affirmative case, the competing perspectives on issues of choice and composition between the two practices would be reduced - and even eliminated - thus contributing to the consolidation of mixed methods, qualitative-quantitative, strategies. Finally, it is worth noting that $\mathrm{CMP}^{\prime} \mathrm{s}$ underlying logic implies the combination of the concept of cause, in its broad sense, with the experimental model and its developments It does not mean, however, to assume that the instrumental role of qualitative methods in the own CMP relies on either the notion of cause, or experiment or whatever comparisons.

Keywords: Quantitative methods. Social sciences. Causal methodological paradigm. Mixed methods. 


\section{Introdução}

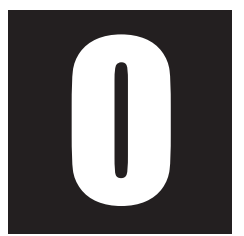

objetivo específico do presente ensaio é a tentativa de uma explicitação esquemática da lógica subjacente aos conceitos e procedimentos da chamada 'metodologia quantitativa' para as ciências sociais, em particular para a sociologia'. Este objetivo se justifica em termos da necessidade, por parte da agenda metodológica das ciências sociais, de identificar explicitamente o potencial e os limites dos dois tipos mais gerais de abordagem metodológica para as ciências sociais, o qualitativo e o dito quantitativo, incluindo também, como opção, o tipo combinado chamado de 'quali-quanti'. A divisão das abordagens de pesquisa entre qualitativas e quantitativas constitui, de fato, uma divisão das práticas de pesquisa, não completamente resolvida nem na sua natureza, nem nas suas interfaces. O presente ensaio pretende realizar uma contribuição para o avanço do tratamento desta questão, sem pretender resolvê-la.

Como ponto de partida, considere-se aqui que as próprias expressões que identificam a divisão em questão correspondem à ideia de que o campo da pesquisa qualitativa se caracteriza, genericamente, pela ausência de números como instrumento e objeto significativos do seu trabalho; e inversamente, que a quantitativa é caracterizada, nesse debate, pela utilização de números como instrumento e objeto básico do seu trabalho. Esta noção é, de fato, equivocada, pelo menos do ponto de vista dos ditos 'métodos quantitativos', como veremos adiante. A apresentação e discussão da divisão metodológica em questão, por exemplo, nos textos didáticos, baseia-se no agrupamento das técnicas de acordo com este critério geral e com alguns objetivos pontuais (como a possibilidade de

\footnotetext{
${ }^{1}$ No presente artigo nos referimos às ciências sociais genericamente, considerando que o argumento em geral seja aplicável a todas elas. Mesmo assim, especificamente foi a prática da investigação causal, em contraste com a não causal, que inspirou o próprio.
} 
aprofundar na captação e compreensão dos significados da ação social) sem, contudo, conseguir traçar um fio condutor das próprias, em termos da sua 'lógica subjacente'. É nesta lógica subjacente que devemos encontrar sua articulação unitária, de forma tal que: a) permita realizar escolhas adequadamente informadas sobre a utilização de uma ou outra delas, ou auxilie nesta escolha, especialmente nos muitos casos em que a quantificação e a análise causal, ou não, não fazem parte do próprio problema de pesquisa; e b) clarifique e estimule a formulação das suas interfaces, tanto dentro de projetos específicos 'quali-quanti' como, num sentido geral, estimulando a formulação das agendas temáticas abrangentes. Lembre-se aqui que as duas abordagens trabalham com 'dados', independentemente das bases epistemológicas e ontológicas últimas a eles imputáveis e das suas fontes, sendo que o 'fato' de serem 'dados' é o seu enquadramento epistemológico chave. Este é, pois, o contexto operativo das ciências sociais onde situamos o objetivo específico deste ensaio.

A pergunta que emerge agora é: que critério(s) podemos utilizar para identificar a presença ou não de uma lógica subjacente unitária dentro das práticas específicas de pesquisa? Para responder a esta questão, recorremos ao trabalho de T. Kuhn sobre os 'paradigmas científicos' $(1975 ; 1977)$. Considere-se aqui, introdutoriamente, que a noção nuclear de 'paradigma', em Kuhn, tem a ver com a ideia de 'modelo exemplar completo', como veremos posteriormente em detalhe. Ora, como hipótese de trabalho, registramos que a metodologia (dita quantitativa, ou seja, o PMC) em questão, também corresponde, em última instância, a um modelo procedimental exemplar, de onde deriva e onde encontra a sua unidade: trata-se do 'modelo experimental', associado às análises 'causais' que o caracterizam.

O enquadramento paradigmático proposto pode ser desdobrado em três questões, diferentes, mas inter-relacionadas, a saber: a) Segue, a abordagem metodológica dita 'quantitativa', uma lógica paradigmática Kuhniana? b) Segue, da mesma forma, a abordagem metodológica 'quali- 
tativa', uma lógica paradigmática Kuhniana? c) Finalmente, dependendo das respostas às duas questões, pode-se ou não encontrar uma lógica paradigmática subjacente articuladora das duas práticas ao redor dos seus objetivos e promessas? Esta é a agenda dentro da qual se situa o presente ensaio. Nele, porém, em função do seu escopo, só abordaremos, e ainda tentativamente, a primeira pergunta, relativa apenas à pesquisa quantitativa, deixando para o futuro as outras duas questões.

De uma forma geral, argumentamos que os elementos apontados por Kuhn $(1975,1977)$ como constitutivos dos paradigmas científicos estão presentes na perspectiva metodológica em questão, que denominamos, a partir daqui, de 'paradigma metodológico causal' (PMC). Há, também, porém, alguns elementos dos paradigmas Kuhnianos que não estão presentes no PMC, em função do seu objeto especificamente metodológico, os quais serão abordados posteriormente. Dentro dessa visão, a questão da relação entre a formulação Kuhniana e o PMC vira uma pergunta concreta de pesquisa, que pode ser analisada dentro do objetivo deste ensaio. Nesse sentido, o presente ensaio pretende mostrar que os chamados 'métodos quantitativos' constituem de fato um paradigma kuhniano, que gravita ao redor da ideia de 'causa'. Esta última, por sua vez, é trabalhada metodologicamente, dentro do paradigma, a partir da lógica unitária subjacente do experimento, entendido basicamente como o tratamento dado a um grupo, e contrastando o resultado deste tratamento com a condição idêntica de outro grupo não submetido, porém, ao tratamento. Ora, a evolução do PMC envolve a superação das noções e práticas clássicas de 'causalidade', até chegarmos ao entendimento contemporâneo, como discutiremos, embora muito resumidamente, ao longo do ensaio ${ }^{2}$.

\footnotetext{
${ }^{2} \mathrm{Na}$ seção seguinte, apresentaremos um resumo esquemático dos elementos-chave da noção de paradigma em Kuhn, para refrescar o leitor sobre este particular. Porém, dito esquema não substitui um conhecimento básico anterior sobre tal interpretação do mundo da ciência, sem o qual a compreensão do presente ensaio provavelmente fica fatalmente prejudicada.
} 
Nossa explicitação da lógica subjacente aos conceitos e procedimentos associados ao PMC gravita ao redor: a) da noção de 'causa'; e b) do procedimento paradigmático essencial, o experimento, embora, na prática, geralmente este seja atingível apenas através dos seus desdobramentos aproximativos (os 'semiexperimentos' e a 'análise correlacional'). Como mostraremos ao longo do ensaio, a lógica paradigmática que liga a noção heurística de 'causa' com o experimento (Cano, 2002) constitui a base última de toda a construção do PMC.

Nossa estratégia para atingir o objetivo de explicitação da lógica subjacente do PMC consiste em repassar os elementos e propriedades principais dos paradigmas Kuhnianos, avaliando a sua pertinência com relação ao PMC. Com esta metodologia, pretendemos avaliar, pois, em que sentido ou medida há uma lógica subjacente e unitária ao alegado PMC, considerando que este representa um 'caso especial' de paradigma científico, pois não envolve 'explicações' de recortes específicos da realidade, mas se refere apenas a modelos e procedimentos genéricos de análise e a técnicas de fornecimento de provas e evidências.

\section{Um Breve Esquema dos Paradigmas Kuhnianos}

À continuação, segue um breve esquema dos elementos básicos dos paradigmas científicos de T. Kuhn como pano de fundo da exposição posterior sobre o PMC.

\subsection{Obras exemplares seminais sobre problemas específicos}

Kuhn estabelece a existência de linhas de produção científica consagradas, pela própria comunidade científica, a partir de critérios internos dos próprios trabalhos, tal e como eles têm sido interpretados e utilizados pela mesma. Estas linhas ou 'paradigmas científicos' derivam de obras 
seminais que lançam padrões de trabalho, incluindo posicionamentos heurísticos (epistemológicos e ontológicos), explícitos e/ou implícitos, e também definições e conceituações consideradas exitosas e férteis em função da sua aplicabilidade e desenvolvimento histórico posterior. Os paradigmas se consolidam, em última instância, como padrões históricos de prática científica, adotados pelas comunidades científicas, as quais se rendem à eficiência e à persuasividade do conjunto dos seus diferentes elementos, os assumem, e os desenvolvem.

Os trabalhos paradigmáticos seminais surgem em função do tratamento de problemas específicos, mas são aplicáveis a uma variedade muito mais ampla de situações e casos. Daí o seu caráter seminal. Ao conjunto de aplicações mais ou menos diretas dos postulados e premissas paradigmáticas realizado pela comunidade científica, desenvolvendo e aperfeiçoando o próprio paradigma, Kuhn (1975) chama de "ciência normal".

\subsection{A matriz disciplinar dos paradigmas}

Os paradigmas incluem um conjunto substantivo de elementos, que responde à seguinte interrogação literal de Kuhn: "O que é que os membros da comunidade [científica] compartilham, e que dá conta da relativa "completude" [do original em inglês fullness] da sua comunicação profissional, e da relativa unanimidade nos seus julgamentos (avaliações) profissionais?" (Kuhn, 1975, p. 182, grifos nossos). A resposta a esta questão constitui o que ele chama de 'matriz disciplinar'.

A ideia de uma matriz disciplinar surge considerando, entre outras coisas, que a noção de "teoria" - a qual pareceria, superficialmente, responder à indagação em questão -, no seu uso mais comum, não inclui alguns elementos subjacentes básicos para a formulação e extrapolação dos seus próprios conteúdos. Quando se pensa na 'matriz disciplinar' de Kuhn, as teorias, de qualquer forma que sejam formuladas ou entendidas 
(incluindo leis, causas, mecanismos, probabilidades, discursos, etc.), ficam de fora, pois estes conteúdos teóricos são polêmicos, debatidos, e ficam em estado permanente de questionamento, avaliação, transformação e/ ou adaptação. Não foram estes conteúdos que se consagraram como modelos de pesquisa, de forma integral, estável e, portanto, paradigmática. Os paradigmas incluem teorias, sim, e inclusive também processos e mecanismos de falsificação. Mas não são as teorias, falsificadas ou não, as que definem os paradigmas 'de princípio a fim', e não são os processos de falsificação per se, os que determinam, em última instância, a dinâmica própria do paradigma, diríamos 'popperianamente'.

Os elementos da matriz disciplinar, então, são de caráter definicional, anteriores às teorias, e incluem: a) modelos heurísticos e ontológicos; b) generalizações simbólicas; c) problemas exemplares; e finalmente, d) valores. No presente ensaio, abordamos apenas os elementos em a) e b) acima, pois os outros dois têm apenas um caráter complementar na ideia de matriz disciplinar, sem importância específica no nosso argumento.

\subsection{Modelos heurísticos e generalizações simbólicas}

Inicialmente Kuhn chamou estes 'modelos' de 'parte metafísica' dos paradigmas, referindo-se à ideia de que, logicamente subjacentes e anteriores aos conteúdos explicativos teóricos dos paradigmas (aludidos anteriormente), estes operam numa base de sustentação última, muito geral, de princípios, conceitos e esquemas conceituais, de corte instrumental ou suposicional, desenvolvidos e articulados por tentativa e erro, e por acumulação de experiências 'ad hoc'. Portanto, não há fórmulas nem premissas específicas definidas para inferir ou derivar os modelos heurísticos. Os modelos heurísticos não sustentam teorias. Eles apenas enquadram e podem aperfeiçoar e mudar a lógica de trabalho das teorias, como no caso da causalidade determinista em Durkheim (1999), que passou para probabilística, como discutiremos posteriormente. 
Além dos modelos heurísticos, os conteúdos teóricos explicativos e práticas científicas que se desenvolvem dentro de um paradigma operam dentro de marcos conceituais mais específicos e formais do que os modelos heurísticos, mas ainda de caráter definicional (no sentido de que não correspondem nem a derivações lógicas, nem a constatações empíricas, mas correspondem, grosso modo, ao comumente chamado, nas ciências sociais, de "marco conceitual"): trata-se das 'generalizações simbólicas' do tipo $f=m$.a (força igual a massa vezes aceleração) na física, citado por Kuhn (1975), as quais expressam definições, em lugar de leis ou regularidades empíricas, e estão associadas aos recortes ou 'segmentos-alvo' das explicações e práticas científicas de interesse do paradigma. A realização destas associações envolve, inexoravelmente, práticas analíticas não codificáveis, e que constituem o 'conhecimento tácito' do paradigma, peça também decisiva na formulação Kuhniana.

\subsection{Desenvolvimento, reajustes, anomalias \\ e rupturas ou 'revoluções científicas'}

Os elementos constitutivos dos paradigmas são desenvolvidos e reajustados pelas comunidades científicas ao longo do seu trabalho de aplicação a problemas e situações novas. Os paradigmas, então, se mantêm, na expressão de Tschannen (1994), como "coleção de modelos exemplares" de prática científica, contanto que a possibilidade que oferecem de dar soluções aos problemas abordados, a partir das bases paradigmáticas fundamentais, seja percebida - e praticada - como a melhor, pelo menos por um segmento relevante da comunidade científica.

Porém, o desenvolvimento dos paradigmas, como 'sistemas' ${ }^{3}$ imperfeitos que são, defronta-se eventualmente com anomalias que mesmo os mais

\footnotetext{
${ }^{3} \mathrm{~A}$ noção de sistema se utiliza aqui no sentido de "sistemas adaptativos recursivos" (Zito, 1984).
} 
idôneos membros da comunidade científica não conseguem resolver. Estas anomalias envolvem problemas ou situações novas que ficam como inconsistências 'à espera' de uma solução pelo próprio paradigma, o qual, 'por enquanto', não tem intrinsecamente condições de assimilá-las. A acumulação de anomalias acaba sendo a força que faz surgir eventualmente a necessidade de uma 'mudança de paradigma' (do inglês paradigm shift); isto é, uma 'revolução científica' que estabeleça novas bases de trabalho, incomensuráveis com relação às anteriores, mas eficazes na solução das anomalias.

A mudança de paradigma, porém, não tem nem poderia ter regras, visto que os critérios de 'validade' do paradigma são apenas internos a ele. Poder-se-á então falar da existência de um novo paradigma, só na medida em que uma comunidade científica significativa, persuadida do maior poder e eficácia explicativos do 'novo' paradigma, tenha passado a aceitar e utilizar um novo conjunto de postulados e procedimentos, dentro dos quais se resolvem mais adequadamente as anomalias surgidas no paradigma anterior ${ }^{4}$. Portanto, a mudança de paradigma no seio da comunidade científica se dá apenas pela capacidade de persuasão da própria obra seminal e das suas possibilidades, aceita na comunidade científica em função do reconhecimento dos seus méritos internos, e não em função de parâmetros ou critérios externos a ela própria ${ }^{5}$. É o que Kuhn denomina 'revolução científica'.

\subsection{Convergência pré-paradigmática}

O desenvolvimento paradigmático da ciência, segundo Kuhn, porém, não tem sido uma regularidade através da história do saber humano. Pelo contrário, só se chegou a esta forma de desenvolvimento, após uma

\footnotetext{
${ }^{4}$ Kuhn (1975) aceita também a importância da revelação de novos fatos como componente importante do novo quadro paradigmático.

${ }^{5}$ Daí a crítica à 'irracionalidade' e 'psicologia de massa' do desenvolvimento científico, levantada contra Kuhn por autores como I. Lakatos (1976).
} 
longa fase 'pré-paradigmática', quando não existia um consenso sobre bases e linhas de trabalho. Nessa fase, a atividade intelectual da comunidade de 'sábios' permanecia atolada em debates sobre diferentes visões do mundo e da forma de se criar conhecimento. Ou seja, faltava um mínimo de consenso epistemológico, ontológico e metodológico que permitisse avançar sistematicamente numa certa direção. Há, pois, historicamente, um momento no qual a 'pré-ciência', para Kuhn (1975), através de um processo de convergência pré-paradigmática, experimentou o lançamento de obras exemplares seminais contundentes, adquirindo, por esta via, sua maturidade e passando a apresentar progressos sistemáticos, embora os consensos ao seu redor não tenham sido absolutos. Nesse período histórico, que coincide com a revolução industrial na Europa, uma série de 'sequências' propriamente paradigmáticas se consolida na comunidade 'científica', deixando as outras correntes à margem da corrente paradigmática básica de pesquisa.

Este fenômeno de convergência paradigmática da ciência moderna inclui, no mesmo processo histórico abrangente, o advento do PMC das ciências sociais e, entre elas, a sociologia. Este tem sido, reconhecidamente, um ponto crucial de discordâncias e críticas epistemológicas e ontológicas ao que denominamos aqui de PMC. Não é este o lugar para aprofundar-nos nestas polêmicas epistemológicas, em que surgem com destaque as obras de K. Marx e, posteriormente, de M. Foucault. Nesse sentido, cabe apenas salientar duas características da convergência préparadigmática do PMC. Uma é que, de fato, a consolidação deste paradigma metodológico acontece, nas ciências sociais, subsequentemente à sua consolidação nas 'ciências naturais' (excluindo destas últimas as ciências sociais); isto, entre outras coisas, em função da maior dificuldade de aplicação do próprio PMC original aos fenômenos do mundo social humano. Mesmo assim, é importante explicitar que o advento do PMC das ciências sociais representa um desdobramento do mesmo PMC das 
ciências naturais, sendo que esta filiação gerou as críticas epistemológicas e ontológicas mencionadas 6 . Outra característica é que o 'consenso' ao redor do PMC pela convergência paradigmática tem sido bem mais frágil no caso das ciências sociais, nas quais, em alguns casos, a predominância do PMC provavelmente não aconteceu, ou não acontece ${ }^{7}$.

\section{Caracterização Kuhniana do Paradigma Metodológico Causal nas Ciências Sociais}

Nesta seção discutiremos o próprio PMC à luz de alguns elementos básicos dos paradigmas Kuhnianos.

\subsection{Obras seminais no Paradigma Metodológico Causal}

Em primeiro lugar, destacamos, como seminais ou 'paradigmáticas' no PMC, as obras de E. Durkheim e M. Weber, considerados aqui os seus 'fundadores'. Resumidamente, estas obras podem ser consideradas paradigmáticas na medida em que: a) estruturaram uma forma 'nova' (apoiadas, é claro, nos seus muitos precursores) de enxergar a questão metodológica das 'relações causais' aplicadas ao mundo social; e b) se consolidaram eventualmente como modelos seminais de prática científica ao redor desta metodologia de pesquisa, e foram seguidas por contin-

\footnotetext{
${ }^{6}$ Estas críticas partem da suposição de que em nenhum sentido e em nenhum momento estratégico da produção do saber há lugar para submeter o mundo social humano aos princípios metodológicos paradigmáticos das ciências naturais. Certamente não é esta uma suposição adequada ao PMC, como os ensaios metodológicos e trabalhos paradigmáticos substantivos de Durkheim e Weber estabeleceram.

${ }^{7}$ Pode-se argumentar que os paradigmas de K. Marx, primeiro, e de M. Foucault, depois, dentro da visão Kuhniana (mesmo não tendo eles uma agenda científica, e inclusive sendo, cada um ao seu modo, crítico dela), não conseguiram passar, na terminologia de Kuhn, de 'desafios paradigmáticos' de profundo valor histórico, mas em última instância fracassados, fundamentalmente, por causa da ausência neles de uma postura metodológica mais consistente.
} 
gentes, se não majoritários (pois na ciência social este tipo de consenso é sabidamente bem mais difícil do que nas ciências naturais), pelo menos altamente expressivos da comunidade científica, na forma do PMC, sofrendo redefinições e adaptações dentro dos seus lineamentos originais ${ }^{8}$.

Quando se fala, porém, em fundadores, particularmente da tradição sociológica abrangente, se inclui indefectivelmente K. Marx, e por razões muito poderosas. Mesmo assim, é obvio que existe um abismo metodológico, entre outros, entre Marx e seus 'colegas fundadores' da teoria social moderna, começando pelo fato de que, em Marx, o modelo 'heurístico' central - se queremos usar este termo - não se constitui nas relações causa-efeito, mas nas relações históricas de hierarquia e condicionabilidade entre diferentes 'estruturas' ('super' e 'infra'), levando o marxismo, talvez exageradamente, ao descrédito de que padece hoje.

\subsection{Componentes dos paradigmas Kuhnianos não presentes no Paradigma Metodológico Causal}

A dinâmica do PMC envolve, como todo paradigma científico, certa evolução dos seus modelos heurísticos e procedimentais, os quais, por razões de exposição, mostraremos depois. Esta evolução paradigmática não vem, no entanto, acompanhada das 'rupturas' ou 'revoluções científicas' que sinalizariam o fim do ciclo de um paradigma e o início de outro, contrariando assim a dinâmica global própria dos paradigmas científicos formulada por Kuhn. Esta particularidade se explica em função de que o PMC envolve, pela natureza do seu objeto, uma proposta puramente

\footnotetext{
${ }^{8}$ É importante notar uma diferença entre o paradigma ou paradigmas metodológicos das ciências sociais, onde a discussão metodológica aparece detalhada e condensada em obras especificamente metodológicas (como as referenciadas acima), de um lado, e os paradigmas das ciências naturais, onde as discussões metodológicas emergem apenas entrelaçadas com os trabalhos teoricamente substantivos, do outro. Isto é consistente com a natureza especificamente metodológica do $\mathrm{PMC}$, e dá respaldo adicional à ideia de um (ou dois) paradigma(s) especificamente metodológico(s) para as ciências sociais.
} 
metodológica e abstrata para o avanço do conhecimento científico, na qual não cabem as 'generalizações simbólicas' emanadas diretamente do mundo empírico, e identificadas por Kuhn na sua matriz disciplinar. Dito de outra forma, a ausência de generalizações simbólicas no PMC deriva da ausência de conteúdos explicativos, os quais, nos paradigmas Kuhnianos, precisam, por sua vez, do tipo de marco definicional que as generalizações simbólicas fornecem, sobre o qual montar as suas explicações, dentro dos seus domínios temáticos. O tipo de domínio temático do PMC não envolve este tipo de explicações.

Em lugar de generalizações simbólicas norteadoras do seu desenvolvimento, o PMC realiza seu objetivo, fundamentalmente, através de modelos procedimentais de fornecimento de evidências do tipo experimental - ou dele derivados, como ilustraremos posteriormente -, os quais, porém, resultam bem mais polêmicos do que o são nas ciências naturais ${ }^{9}$. À continuação, discutiremos esquematicamente alguns modelos procedimentais básicos de captação da realidade empírica ao redor do mencionado procedimento experimental de fornecimento de provas e de evidências, junto com alguns fundamentos heurísticos correspondentes ao modelo experimental, ao redor da relação causa-efeito, no PMC.

\subsection{Componentes básicos, heurístico e procedimental do Paradigma Metodológico Causal nos seus fundadores}

No contexto do PMC, as obras de E. Durkheim e M. Weber adquirem importância paradigmática com relação às questões da lógica experimental subjacente aos métodos por eles utilizados quando abordaram

\footnotetext{
${ }^{9}$ No domínio temático das ciências sociais, os modelos em questão envolvem ainda questionamentos ao redor da lógica heurística causal, e de questões operacionais sobre a validade e confiabilidade deste método de trabalho com seres humanos, numa postura 'pré-galileica', em que, falando figurativamente, a natureza ainda gira ao redor do homem, e não o contrário.
} 
questões permeáveis à análise causal. No caso de Durkheim (1999, p. 130), a seguinte citação ilustra bem o sentido heurístico da sua noção de causa: [...] somente os filósofos puseram em dúvida a inteligibilidade da relação causal. Para o cientista, ela não se questiona; ela é suposta pelo método da ciência. Em Durkheim, a relação causa-efeito, porém, não foi mais entendida nos termos antropomórficos da tradição filosófica anterior a J. S. Mill, mas em termos 'científicos'; isto é, ela supõe 'forças inerentes' aos fenômenos naturais, que 'produzem' efeitos específicos em outros. Estas forças podem ser inferidas a partir dos seus próprios efeitos, como é o caso da 'força' atribuída por Durkheim aos fatos sociais. A noção durkheimiana de causa estava ainda, porém, atrelada ao componente 'unicausalista' (um efeito específico vindo apenas de uma única causa) da visão antropomórfica mencionada (de Aristóteles e Copérnico), resistindo à formulação 'pluricausalista' de Mill (Durkheim, 1999), que é geral hoje na pesquisa. Ao mesmo tempo, Durkheim (desta vez junto com Mill) fica preso também à caracterização 'determinista' da noção de causa - como na sua análise do Suicídio (1966). Isso resulta na postulação da causalidade como uma relação ao mesmo tempo necessária e suficiente, a qual é contrária à maioria das observações ligadas a esta questão hoje (Cano, 2002) (voltaremos a isto depois).

É importante registrar, também, que a posição unicausalista/determinista de Durkheim se fundamentou não só na natureza do laço entre a causa e o efeito (comunalidades e afinidades fenomenológicas), mas também na complexidade metodológica 'incontrolável' que se gera, nessa visão, com a introdução do pluricausalismo. Referindo-se ao pluricausalismo de Mill, Durkheim (1999, p.129) escreve: Esta concepção do vínculo causal, retirando-Ihe todo poder determinante, torna-o praticamente inacessível à análise científica, pois introduz tais complicações na trama de causas e efeitos que o espírito nela se perde sem retorno. Aqui, Durkheim 
intuiu um problema real, sobre o qual C. W. Mills (1959) mais tarde alertava, referindo-se ao indeterminado número de variáveis independentes que podem ser introduzidas nas análises causais empíricas. Este é o quid pro quo presente na flexibilização probabilística pós-durkheimiana dos fatores etiológicos no PMC, sendo que, naturalmente, as alternativas possíveis de condições suficientes de ocorrência serão menores, quanto mais estreitamente seja especificado o efeito a ser analisado.

Ainda, mesmo dentro da sua concepção filosófica da causalidade, o modelo heurístico/operacional da relação causa-efeito em Durkheim envolveu também as questões de causalidade espúria, causalidade condicional e, inclusive, os rudimentos procedimentais do que mais tarde foi chamado - e operacionalizado matematicamente por Simon (1957) - de 'estruturas causais', como veremos posteriormente. Neste ponto, os desenvolvimentos técnicos (estatísticos e computacionais) acabaram abrindo possibilidades enormes ao PMC, aparentemente ditando o seu rumo principal de evolução, tal é a capacidade 'preditiva' destas estruturas, frente aos efeitos seletivos de 'causas' macrossociais, como são as dimensões normativa (coesão social) 'anomia/fatalismo', e integrativa 'egoísmo/altruísmo', com relação ao próprio suicídio.

Do ponto de vista procedimental, a maior limitação de Durkheim foi, possivelmente, a ausência do conceito de variável, através da qual o PMC, pouco depois, deslanchou empiricamente, na linha antes indicada. Mesmo assim, Durkheim conseguiu, mesmo com instrumentos conceituais muito rudimentares, montar um modelo procedimental suficiente para chegar à formulação operacional básica do PMC. Vejamos esquematicamente os elementos essenciais desta questão procedimental.

Em primeiro lugar, lembramos que Durkheim (1999, p. 136) aceita a possibilidade de aplicação do método experimental de Mill na sociologia (e por extensão nas ciências sociais), mas já apontando as suas fragilidades: 
Na verdade, o que muitas vezes desacreditou o raciocínio dos sociólogos é que, por terem empregado de preferência ou método da concordância ou da diferença [...] eles se preocuparam mais em acumular documentos do que em criticá-los e escolhê-los. ... Diante de tais demonstrações, não apenas somos levados a afirmar que um único fato poderia ser suficiente para invalida-las [as conclusões], mas também que os próprios fatos sobre as quais são estabelecidas nem sempre inspiram confiança.

Para Durkheim (1999, p. 133), o método das variações concomitantes acaba sendo o método essencial e quase único que a sociologia pode utilizar, pois, nas suas palavras,

[...] para ser demonstrativo, não requer que todas as variações diferentes daquelas que se comparam [ seguindo os cânones de Mill], tenham sido rigorosamente excluídas. O simples paralelismo dos valores pelos quais passam os dois fenômenos, contando que tenha sido estabelecido num número suficiente de casos suficientemente variados, é prova de que existe entre eles uma relação.

Posteriormente, no mesmo texto, sem utilizar especificamente a noção de variável, Durkheim (1999, p.138) se refere implicitamente a ela, arrematando assim seu argumento: O que é preciso é comparar não variações isoladas, mas séries de variações regularmente constituídas, cujos termos se ligam uns aos outros por uma gradação tão contínua quanto possível e que, ademais, tenham uma extensão suficiente. Ora, Durkheim não só deu a fórmula nuclear para isto nas suas 'Regras...' (1999), mas a colocou em prática com sucesso paradigmático, especialmente na sua obra O Suicídio (1966).

A pergunta que naturalmente surge aqui é: onde fica a prometida lógica subjacente unitária do PMC em seus fundadores? Trata-se de experimentos ou de variações concomitantes? A resposta a esta questão é simples, e pode ser resumida dizendo-se que os cânones de Mill, e 
o método experimental em geral, envolvem também, de fato, variações concomitantes: na sua forma mais elemental, o experimento corresponde à variação na variável independente dicotômica (presença ou ausência do tratamento) concomitante com a variação na variável dependente (presença ou ausência do efeito). Inversamente, pode-se dizer que uma correlação entre variáveis contínuas (independente e dependente) corresponde a uma extensão da lógica de um experimento. Nas palavras de Selltiz, Wrightsman e Cook p. 51), citados por extenso:

Um delineamento comum de pesquisa de levantamento que procura explicar e interpretar relações, está muito próximo de um dos delineamentos pré-experimentais de Campbell e Stanley [JMFM: 1966] - a comparação com o grupo estático.

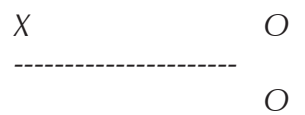

Se imaginamos um delineamento com um $X$ que ocorra naturalmente em vários níveis (por exemplo sexo masculino e feminino, ou nível sócio-econômico baixo, médio, alto), este se transforma no seguinte:

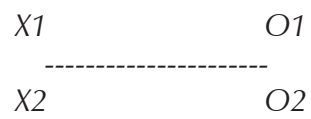

Este delineamento mostra dois grupos de comparação [não casualizados], definidos por seu valor de ' $X$ '. Podem-se comparar os escores ' $O$ ' nos dois grupos para verificar se há uma relação entre ' $X$ ' e ' $O$ '. Suponha que ' $X$ ' nesse diagrama represente a ocupação (operário e funcionário de escritório), e ' $\mathrm{O}$ ' represente a renda. Se os grupos diferirem na renda será tentador interpretar esta diferença como o efeito da ocupação sobre a renda. Tal interpretação seria análoga à interpretação dos efeitos de ' $X$ ' num experimento. 
É claro, então, que há uma diferença entre a comparação com o grupo estático do pré-experimento de Campbell e Stanley (1966) e um delineamento que ocorra naturalmente em vários níveis, indicado na comparação anterior. Mesmo assim, a lógica subjacente é a mesma, derivada do experimento e dos cânones de Mill. Portanto, Durkheim, sem negar o papel possível das investigações causais na sociologia pelas vias experimentais, mas apontando para a sua dificuldade na prática investigativa, não apenas postulou que as variações concomitantes deveriam ser a verdadeira e sólida base da metodologia empírica causal sociológica, mas realizou com sucesso sem precedentes o trabalho seminal para tal agenda. Finalmente, não pode faltar menção, pelo menos, do fato que no trabalho de Durkheim estiveram presentes já as noções e procedimentos rudimentares de causalidade espúria e condicionalidade causal. Textualmente, nas suas 'Regras...', Durkheim (1999, p.134) formula a sua prática metodológica básica exercitada em O Suicídio assim:

Quando dois fenômenos variam regularmente tanto um quanto outro, é preciso manter esta relação, ainda que, em alguns casos, um desses fenômenos se apresentasse sem o outro. Pois pode ocorrer, ou que a causa tenha sido impedida de produzir seu efeito pela ação de alguma causa contrária, ou que ela se encontre presente, mas sob uma forma diferente daquela anteriormente observada. Sem dúvida, é o caso de conferir, como se diz, de examinar os fatos, mas não de abandonar de vez os resultados de uma demonstração regularmente conduzida.

E agrega:

É verdade que as leis estabelecidas por esse procedimento nem sempre se apresentam de imediato sob a forma de relações da causalidade. A concomitância pode ser devida, não a um fenômeno ser causa de outro, mas a serem ambos efeitos de uma mesma causa, ou então por existir entre eles um terceiro fenômeno, intercalado, mas despercebido, que 
é o efeito do primeiro e a causa do segundo. Os resultados a que esse método conduz têm por tanto a necessidade de serem interpretados. Mas qual o método experimental que permite obter mecanicamente uma relação de causalidade sem que os fatos que ele estabelece precisem ser elaborados pelo espírito? (Durkheim, 1999, p.134, grifo nosso) ${ }^{10}$.

O esqueleto do PMC estava construído.

\section{As estratégias qualitativas do paradigma metodológico causal nos seus fundadores}

Além do papel central da lógica experimental e das 'variáveis' quantitativas no tratamento das questões permeáveis à análise causal, é importante registrar, ainda como parte dos modelos procedimentais do PMC, o papel bastante relevante em Durkheim, e definitivamente central em Weber, da utilização de estratégias metodológicas qualitativas, também com relação à realização das suas investigações causais.

Começamos fazendo uma referência ao objeto e instrumentos analíticos do trabalho clássico de M. Weber, 'A Ética Protestante e o Espírito de Capitalismo' (1985) ${ }^{11}$. Esse trabalho sabidamente envolve um dos exercícios mais intrincados, lógicos e frutíferos já elaborados de imputação e

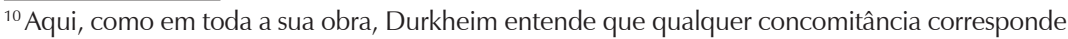
a uma 'lei' da natureza. Porém, dentro da sua linha conceitual ou filosófica, referida atrás com relação às 'causas', esta concepção acaba sem consequências operacionais nas investigações.

${ }^{11} \mathrm{O}$ escopo deste ensaio é insuficiente para tratar da questão da metodologia dos tipos ideais na sua interface com o PMC. É suficiente para os presentes propósitos registrar que o tratamento causal de questões sociológicas históricas se realiza, mesmo com anterioridade à formulação explícita de Weber, fundamentalmente a través de tipos ideais, atendendo simultaneamente às necessidades de simplificação da realidade histórica para análise, e de comparabilidade entre os diferentes recortes selecionados para as análises específicas. O estudo da Ética Protestante, em pauta, é um caso exemplar, embora a natureza típico-ideal da metodologia não seja explicitamente reconhecida pelo autor.
} 
articulação de significados recônditos, não só no sentido individual, mas também para agregados sociais, com relação ao lugar e momento histórico especificamente abordado (o último quarto do século XIX, aproximadamente). Esta obra clássica reconhecidamente foi realizada dentro de padrões exemplares de pesquisa qualitativa, do ponto de vista da captação/imputação de constelações de significados a um 'histórico único'. Mesmo assim, fora alguns dados estatísticos apresentados em caráter introdutório - num sentido descritivo e não analítico -, Weber realiza nessa base uma análise causal qualitativa, ou seja, inteiramente sem uso de números, mas utilizando, isto sim, a lógica experimental das investigações causais. Lembremos que Weber conclui, em seu estudo, que a ética protestante é o único componente típico-ideal do capitalismo em pauta; que está presente, junto com o capitalismo, no contexto indicado, comparado com uma variedade de contextos históricos onde aparecem os outros componentes do seu capitalismo típico-ideal, embora em nenhum destes outros contextos o fenômeno em pauta tenha aflorado.

Obviamente, a fórmula metodológica da 'Ética Protestante' se enquadra nitidamente no trabalho de Mill sobre os seus cinco 'Cânones' para estabelecer causalidade. Portanto, a partir de Weber, fica paradigmaticamente estabelecido que não somente não há necessidade lógica de que as investigações 'causais' sejam só quantitativas (não no sentido da utilização de 'variáveis' qualitativas, mas no sentido da captação 'qualitativa' da realidade), mas também que a utilização de dados e 'técnicas' qualitativas é possível e altamente frutífera com relação à pesquisa de relações sociais causais.

Vale a pena salientar que a estratégia weberiana qualitativa para análise causal foi possível, em função de que a ideia de 'experimento' é logicamente anterior à ideia de quantificação, e que as alterações no efeito do 'tratamento', resultantes do experimento, podem ser tanto 
quantitativas quanto qualitativas (Weber, 2011; 2001). Registremos aqui, também, que o procedimento de 'casualização', porta de entrada das quantificações nos modelos experimentais, representa apenas uma estratégia de controle, não necessária neles, e que serve 'só' para aprimorar - mesmo que decisivamente - a questão da equivalência e validade das comparações entre os grupos experimental e de controle. Então, a obra de Weber, e mais especificamente a investigação citada, ilustrou 'paradigmaticamente' como se podia levar adiante uma pesquisa qualitativa causal, a partir da lógica experimental, tendo naturalmente que se ajustar às condições específicas, sociais e históricas, do seu objeto ${ }^{12}$.

Além da questão da relação entre estratégias metodológicas qualitativas e análise causal, referida com relação a $\mathrm{M}$. Weber, a literatura dos fundadores, desta vez novamente em Durkheim, trabalha a questão da relação entre as estratégias quantitativa e qualitativa, ainda de outro ângulo. Surpreendentemente, não se trata aqui apenas da ideia de que as observações ou imputações de corte 'qualitativo', tomadas como proposições, podem ser permeáveis a quantificações e à análise causal, coisa reconhecida hoje (Cano, 2002): trata-se desse tipo de ligação, sim, mas na direção contrária, isto é, análises quantitativas sendo 'complementadas' - e até reforçadas(!) - por estudos qualitativos.

De fato, já nos primórdios da fundação do PMC, esta interface 'quanti-quali' (nesta ordem) aparece bem ilustrada por Durkheim (1966) em seu estudo do suicídio. Este ponto, bastante - se não totalmente esquecido na pesquisa contemporânea, merece uma breve referência. Após analisar pormenorizadamente suas três 'famosas' formas principais do suicídio como fato social (agregado), a partir de dados e técnicas quan-

\footnotetext{
${ }^{12}$ Weber dá um rigoroso e complexo tratamento a esta questão da causalidade histórica 'qualitativa', que não cabe no escopo do presente ensaio abordar, mas que representa uma dimensão altamente significativa do PMC. Ver Weber $(2011 ; 2001)$.
} 
titativas simples (Livro II, capítulos 1 a 5), o autor aborda a questão do suicídio em nível qualitativo individual no capítulo 6 (intitulado 'Formas Individuais dos Diferentes Tipos de Suicídio'), com uma discussão sobre o complexo trânsito entre os níveis individual e agregado. Estes níveis correspondem, neste caso, às dimensões qualitativa e quantitativa, respectivamente, do fenômeno. Esta correspondência entre níveis de agregação e papéis causais dos fenômenos é central na interface 'quanti-quali'. Isto, principalmente, notando que não estão presentes aqui, nem o problema da 'falácia ecológica', nem o do 'reducionismo', na medida em que Durkheim não extrapola os resultados etiológicos obtidos de um nível de agregação para outro. Durkheim fala na 'marca' ou 'qualidade' que se espera seja deixada pelo nível agregado superior no fenômeno no nível inferior de agregação, mas esta marca não constitui uma extrapolação explicativa, reducionista, exaustiva e, portanto, falaciosa, de um nível pelo outro. Mesmo sem espaço aqui para tratar extensivamente do assunto, bem vale a pena citar por extenso os seguintes dois parágrafos com que Durkheim (1966, p. 277-278) abre o texto em questão: ${ }^{13}$

Um resultado agora sobressai proeminentemente da nossa investigação [até o capítulo 5 -Livro II, quando ainda a pesquisa qualitativa não tinha sido realizada] a saber: não há uma, mas várias formas de suicídio [no sentido agregado do fenômeno, incluindo os tipos anômico, egoísta e altruísta]. Com certeza o suicídio é sempre ato de um homem que prefere a morte sobre a vida [no sentido individual]. Mas as causas que o determinam [novamente no sentido agregado] não são do mesmo tipo em todos os casos [portanto, Durkheim supõe que a cada tipo agregado do fenômeno, corresponde uma causa]. Elas são, algumas vezes, inclusive mutuamente opostas [por exemplo, a do altruísmo versus a do egoísmo]. Agora, tais diferenças em causas devem re-

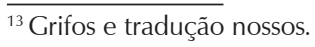


aparecer nos seus efeitos. Podemos portanto ter certeza de que há vários tipos de suicídio [novamente no sentido agregado], os quais são distintos em qualidade uns dos outros [ou seja, cada tipo agregado é identificável por uma qualidade específica nos casos individuais, sendo que esta qualidade individual corresponde à causa específica agregada do tipo]. Mas a certeza de que estas diferenças qualitativas existem [em nível individual] não é suficiente; precisamos observá-las diretamente e saber em que consistem. Precisamos ver as características de suicídios especiais agrupados em distintas classes [em nível individual, diferentes dos 'tipos' inferidos a partir das análises quantitativas], correspondentes aos tipos agora [neste estudo] distinguidos. Para tanto devemos acompanhar as varias correntes ['sociais'] ${ }^{14}$ que geram suicídio, partindo das suas origens sociais [sentido agregado] e chegando às suas manifestações individuais.

Esta classificação morfológica ['não causal', baseada em formas individuais qualitativas de suicídio], que era dificilmente possível no início deste estudo, pode ser realizada agora, quando uma classificação etiológica [nível agregado] forma a sua base. De fato, só precisamos começar com os três tipos de fatores que temos atribuído ao suicídio [nível agregado] e descobrir se as várias propriedades que ele assume na sua manifestação em pessoas individuais podem ser derivadas dos tipos de fatores em questão [nível agregado] e, sendo o caso, como. Com certeza, não todas as peculiaridades que o suicídio pode apresentar [nível individual] podem ser deduzidas desta maneira; isto por que podem existir algumas que dependem somente da própria natureza da pessoa. Cada vítima de suicídio dá ao seu ato um selo pessoal, o qual expressa o seu temperamento, as condições especiais nas quais ele(a) estava envolvido, e as quais consequentemente não podem ser explicadas pelas causas sociais e gerais do fenômeno. Mas estas causas devem marcar os suicídios que elas determinam com uma sombra toda própria sua, uma marca expressiva de cada uma. Esta marca coletiva, nós devemos encontrar.".

$\overline{{ }^{14} \text { Ver Durkheim, } 1999 .}$ 
O texto Durkheimiano subsequente (no mesmo capítulo 6), não deixa dúvidas: a 'marca' que o autor buscava a posteriori, via pesquisa qualitativa, foi encontrada, sustentando e complementando o modelo etiológico em pauta, embora tenha sido de forma muito pouco rigorosa, metodologicamente falando, como o próprio Durkheim (1966) reconhece. Este resultado ilustra de forma irrefutável que a pesquisa qualitativa pode também 'reforçar' e enriquecer empiricamente resultados de análises quantitativas.

\section{Algumas direções mais relevantes em que têm evoluído os modelos heurísticos e procedimentais do Paradigma Metodológico Causal}

É obvio que o PMC das ciências sociais, a partir dos seus fundamentos seminais, e emprestando de outras disciplinas, tem avançado consideravelmente, heurística e procedimentalmente, superando os mestres fundadores. Como uma das mais importantes - se não a mais importante - evolução heurística do PMC, podemos destacar a nova noção de causalidade probabilística, acompanhada, ou talvez até inspirada, pelas formulações matemáticas das probabilidades na estatística. Toda a trama conceitual e filosófica armada historicamente ao redor da noção de causa converge contemporaneamente numa direção, nas palavras de Cano (2002, p. 16): [...] a causalidade nas ciências sociais é, na maioria das vezes, probabilística, e não determinista, ou seja, a presença da causa incrementa a probabilidade de se obter o efeito, mas não o garante.

Esta noção de causalidade probabilística vem ao encontro da ideia de Mill de 'multicausalidade' (um mesmo efeito pode ser decorrência não só de uma, mas de várias causas) ${ }^{15}$. Assim, virtualmente prescinde-se da

\footnotetext{
15 É pertinente notar que a implantação da visão e métodos multicausais não representa uma invalidação dos resultados dos modelos unicausais Durkheimianos, onde o efeito de diferentes
} 
procura por causas últimas ou necessárias, entendendo-se que há um indeterminado número de combinações de fatores que 'influenciam' os fenômenos de interesse, e de condições que modificam estas influências 'interativamente' (no sentido estatístico deste termo). Em particular, com relação à questão das políticas públicas, trabalha-se hoje, em última instância, com a ideia de 'causas eficientes' (no sentido da filosofia científica de Newton, onde as causas são entendidas como mecanismos de alterar a inércia).

Esta evolução toda levou o PMC, naturalmente, de volta ao velho problema da 'seleção' dos fatores causais de Mill, numa nova 'fase' heurística do PMC já vislumbrada por Durkheim, a saber: a ideia das estruturas ou 'modelos' causais. Por modelo causal, então, se entende um conjunto de fatores explicativos selecionados, os quais produzem um efeito ou, melhor dizendo, têm um poder preditivo sobre o 'comportamento' de uma variável dependente. Nesta nova fase, são os interesses específicos do investigador e as condições específicas dos contextos analisados que direcionam a chamada 'especificação' do modelo (seleção das variáveis). Isto, é claro, em conjunção com o tratamento da questão das variáveis espúrias e da 'redundância causal' (as causas singulares, não se excluindo mutuamente, podem, porém, exibir um grau elevado de 'redundância' ou 'multicolinearidade' no seu conjunto, causando 'vieses inflacionários' nos coeficientes dos modelos).

Do lado procedimental, a multicausalidade probabilística encontrou sua operacionalização clássica na incorporação da 'regressão múltipla' à pesquisa social, com a sua capacidade de auferir a 'variância total explicada' (pelo conjunto dos fatores incluídos) na variável dependente, e realizar a 'partição' desta variância explicada, segundo cada um destes

causas supostamente corresponde a diferenças em 'qualidade' desse efeito. Tal é o caso das várias 'qualidades' ou tipos de suicídio. Esta diferença tem a ver principalmente com a delimitação da variável dependente e com a concepção filosófica das 'causas', mas não acarreta consequências na própria validade e tratamento dos modelos causais pela ótica de Durkheim. 
fatores ou variáveis independentes. Este 'multicausalismo multivariado' acabou transformando ou desdobrando a velha ideia das variações concomitantes, central em Durkheim, no 'tripé básico' dos delineamentos de pesquisa no $\mathrm{PMC}$, hoje, a saber:

a) $\mathrm{O}$ 'experimental' propriamente dito, caracterizado na sua fórmula essencial pela formação dos grupos 'equivalentes' - experimental e de controle -, sendo que um, o 'tratamento', hipoteticamente causal, é aplicado ao grupo experimental. Neste delineamento (já reconhecido por Durkheim), estão presentes os três requisitos básicos de Mill, a saber: covariação, sequência temporal, e ausência de hipóteses alternativas (outros fatores).

b) $\mathrm{O}$ 'semiexperimental', caracterizado pela ausência de um dos requisitos dos experimentos apontados acima. Aqui cabe registrar que a pesquisa causal de avaliação, na sua forma mais idônea enquadrase dentro deste tipo de delineamento, sendo que cada 'política' ou 'programa' específico em pauta representa o tratamento semiexperimental e o grupo de controle idealmente é montado a partir das técnicas recentemente desenvolvidas de 'pareamento' amostral.

c) O 'correlacional'16, caracterizado pela avaliação estatística da covariação entre variáveis, seja no sentido 'transversal' ou no de 'painel', segundo se trate de um único momento no tempo ou de dois ou mais (Kidder, 1987). Aqui cabe uma referência à questão

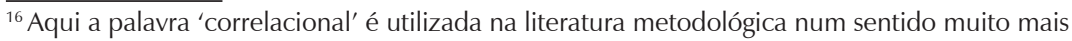
amplo que o relativo aos coeficientes estatísticos de correlação, envolvendo todo o universo de técnicas de aferição de variações concomitantes, inclusive os modelos estruturais introduzidos posteriormente. A compreensão do argumento central neste ensaio passa pela ideia de que estes métodos 'correlacionais' (geralmente derivados de 'surveys' ou 'levantamentos de campo') participam da mesma lógica subjacente dos experimentos, como indicamos anteriormente utilizando as próprias palavras De Selltiz, Wrightsman e Cook. na seção 3.3. Aí fica explícita a passagem do experimento para técnicas multivariadas, dentro da mesma lógica subjacente.
} 
do conhecimento tácito (já mencionado anteriormente), no sentido de que, formulado inicialmente um problema de pesquisa, seja ele de caráter prático ou teórico, não há, em princípio, fórmulas que permitam determinar qual tipo de delineamento cabe melhor ao problema, incluindo, é claro, opções qualitativas. Isto, a não ser que, tautologicamente, se tenha definido a priori o próprio tipo de delineamento e/ou dados a serem coletados. Não sendo este último o caso, só o conhecimento tácito, adquirido através da experiência de pesquisa, não transmissível via conhecimentos 'codificados', mas apenas via supervisão didática de tentativas e erros, pode fornecer bases mais confiáveis para a tomada deste tipo de decisões. Por sua vez, a ausência de fórmulas e a necessidade deste conhecimento tácito derivam do fato de que os problemas novos com que se defronta o pesquisador frequentemente não podem ser enquadrados dentro de categorias ex-ante, ou seja, por antecipação, precisamente por serem elas novas ou, melhor dito, imprevisíveis. Esta é uma das grandes dificuldades que enfrenta a metodologia das ciências sociais quando subdividida a priori nas 'especialidades' qualitativa e quantitativa, tirando assim do pesquisador uma base suficientemente ampla para adquirir este conhecimento tácito, indispensável para um processo de tomada de decisão metodológica sadio.

Finalmente, no que se pode considerar como a fase mais recente do desenvolvimento do PMC, aparece uma preocupação causal adicional à simples introdução de fatores explicativos de um fenômeno dado 'dependente': trata-se da questão do 'processo' de relações e inter-relações, presente entre os próprios fatores, implicando na especificação de variáveis dependentes intermediárias, que agem tanto como dependentes quanto como independentes, segundo a sua posição na 'trajetória causal' especificada pelo modelo. Portanto, as ideias seminais de Durkheim relativas 
à questão das 'estruturas causais', são retomadas e elaboradas pelo PMC em termos, inicialmente, de regressão múltipla, e posteriormente, dos modelos causais chamados 'de trajetória'.

Estes desenvolvimentos do PMC levaram seus praticantes a um outro salto procedimental de especial relevância na sua história recente: foi a operacionalização matemática das próprias estruturas causais, via a especificação da 'normalidade' e independência dos erros (Simon, 1957), e a sua incorporação na pesquisa sociológica via a formulação de equações estruturais. Um exemplo paradigmático deste desenvolvimento foi o trabalho sobre a estrutura ocupacional Norte Americana e, em particular, o seu processo causal de estratificação, realizado por Blau e Duncan (1967). A partir daqui, chega-se finalmente à concepção e operacionalização de estruturas causais complexas, incluindo variáveis latentes, com o concurso da análise fatorial (Schumacker; Lomax, 1999). Para chegar a este ponto do seu desenvolvimento, o PMC continuou, é claro, a contar com o concurso do crescimento notável dos recursos computacionais e de programação, sem os quais estes desenvolvimentos não teriam sido possíveis.

\section{Considerações finais}

Se o texto anterior representa, de fato, a explicitação de uma lógica interna do PMC, então se está em posição de trabalhar de forma semeIhante às práticas de pesquisa qualitativa, em dois sentidos diferentes. Um, fundamentalmente, de determinar se as práticas qualitativas obedecem a uma lógica paradigmática (Kuhniana) subjacente, traçada já em obras seminais exemplares completas, especificamente em termos de modelos e princípios heurísticos e procedimentais, e na ausência de 'anomalias' e 'revoluções científicas'. Outro, de determinar, como no caso ilustrado da complementação qualitativa das análises quantitativas do suicídio em 
Durkheim, discutidas no texto acima, se a natureza paradigmática dos métodos qualitativos, caso confirmada, se coaduna com o PMC; isto é, se a interface entre as duas abordagens permite construir uma lógica 'metodológica' unitária para a pesquisa, que reduza, ou até elimine, as respostas antagônicas a questões de escolha, combinação, e 'fertilização cruzada' das suas práticas. Não se quer afirmar aqui que todos os praticantes da investigação social concordem em que a especialização metodológica básica qualitativa versus quantitativa de hoje seja necessariamente conflituosa, mas sim que falta uma precisão e uma clareza quanto aos limites e possibilidades das duas abordagens, tanto por parte de cada uma isoladamente, quanto, especialmente, em termos das suas interfaces. Desta forma, abriríamos o caminho para a especificação da natureza orgânica - ou não - das duas abordagens consideradas no início deste ensaio.

\section{Referências}

1. BLAU, Peter; DUNCAN, Otis. The American Occupational Structure. New York: The Free Press, 1967.

2. CAMPBELL, Donald Thomas.; STANLEY, Julian Cecil. Experimental and Quasiexperimental Designs for Research. Chicago: Rand McNally, 1963.

3. CANO, Ignacio. Introdução à Avaliação de Programas Sociais. 2. ed. Rio de Janeiro: FGV, 2002.

4. DURKHEIM, Emile. As Regras do Método Sociológico. São Paulo: Martins Fontes, 1999.

5. DURKHEIM, Emile. Suicide: A Study in Sociology. New York: The Free Press 1966.

6. KUHN, Thomas. The Essential Tension. Chicago: The University of Chicago Press, 1977.

7. KUHN, Thomas. The Structure of Scientific Revolutions. 2nd ed. New York: Praeger, 1975.

8. LAKATOS, Irme. The Methodology of Scientific Research Programs. London: Cambridge University Press, 1976. 
9. MILLS, Charles Wright. Sociological Imagination. New York: Oxford University Press, 1959.

10. SCHUMACKER, Randall; LOMAX, Richard. A Beginner's Guide to Structural Equation Modeling. Mahwah, NJ: Lawrence Erlbaum Associates, 1996.

11. SELLTIZ, Claire; WRIGHTSMAN, Lawrence; COOK. Delineamentos de Pesquisa. São Paulo: Pedagógica Universitária, 1987. Organizador Louis Kidder. (Métodos de Pesquisa nas Relações Sociais, v. 1).

12. SIMON, Herbert. Models of Man: Social and Rational-Mathematical Essays on Rational Human behavior in a Social Setting. New York: Martinez Books, 1957.

13. TSCHANNEN, Oliver. Paradigms and Exemplars in Sociology: a Kuhnian Reformulation. Revue Suisse de Sociologie, v. 20, n. 2, p. 463-486, 1994.

14. WEBER, Max. A Ética Protestante e o Espírito do Capitalismo. 4. ed. São Paulo: Pioneira, 1985.

15. WEBER, Max. Methodology of the Social Sciences. New Brunswick, NJ: Transaction Publishers, 2011.

16. WEBER, Max. Objective Possibility and Adequate Causation in Historical Explanation. In: MARTIN, Michael; MCINTYRE, Lee. (Eds.) Readings in The Philosophy of Social Science. Cambridge: MIT Press, 2001.

17. WITTGENSTEIN, Ludwig. Philosophical Investigations. Translation by G.E.M. Anscombe. New York: McMillan, 1999.

18. ZITO, George. Systems of Discourse. London: Glencoe Press, 1984.

Recebido em: 19/05/2012

Aceite final: 24/07/2012 